\title{
VIRTUAL EVOLUTION - A MEMETIC CRITIQUE OF GENETIC ALGORITHMS IN DESIGN
}

\author{
CHRIS ABEL \\ Faculty of Architecture \\ University of Sydney \\ NSW 2006, Australia \\ chrisabel77@yahoo.com.au
}

\begin{abstract}
This paper discusses some issues in design theory arising from the use of genetic algorithms in architecture. The rationale for such programs derives from the iterative process of Darwinian natural selection, which has been likened to an algorithm, or 'foolproof recipe'. However, while the products of these programs are often visually seductive, researchers rarely question the biological model underpinning them. Approaching the subject from a memetic perspective, the author argues that there are fundamental differences as well as similarities between memes, as cultural replicators, and genes, as biological replicators. Evolutionary design models based on the latter, especially those operating exclusively within laboratory or artificial environments, may therefore be misconceived. A number of problematic issues are identified, involving questions of definition, transmission, embodiment, selection and autonomy. As an alternative strategy, it is suggested that embedding design algorithms in real-life projects offers more promising results. The author concludes that, given the complexity of cultural evolution, the proper subjects for design research are memetic algorithms, rather than the genetic models.
\end{abstract}

Keywords: Design theory; biological models; virtual evolution; genetic algorithms; memetics

\section{Biological models}

In my paper I shall try to resolve some questions concerning the current use and misuse of biological models in design, and genetic algorithms in particular, as exemplified in a presentation given by Greg Lynn a few years ago in Sydney. The presentation was one of several offered here in conjunction with the Houses of the Future exhibition in 2004, which focussed, as such exhibitions do, on the impact of new technologies on the shape of residential architecture (Stace). Lynn's contribution consisted of the Embryologic House, a series of computer-generated variations of the now familiar blob-like forms associated with such experiments, the identity and differences between which he clearly struggled to explain.

To his credit, Lynn made no attempt to conceal his dilemma, and recounted an exchange with Peter Eisenman following a similar presentation, in which Eisenman accused Lynn of having "lost all powers of discrimination". Lynn responded that: "They are like my children. I love them all equally". Earlier in his talk, Lynn had also recounted how new technologies of production were being devoted to manufacturing meaningless variations of the same basic product 
designs, common examples of which, he noted, were the countless numbers of barely distinguishable toothbrushes now available to consumers. Yet, despite all the self-conscious and good-humoured acknowledgement of the problem, when it came to explaining the logic behind his house designs, Lynn had not a single word to offer at any point in his exposition regarding either the purpose or the material properties of the curved shapes his program was producing. I concluded that the Embryologic House, like so many similar experiments, was a perfect example of what I now call 'toothbrush architecture'.

Underlying Lynn's difficulties, and the use of similar design programs based on genetic algorithms (DeLanda; O'Reilly, Hemberg and Menges), is the problem of selection. If such programs, which are supposedly modelled on Darwinian theories of evolution, are to be effective, then the criteria of selection and related factors involved have to approximate in some meaningful way to real-life processes, which in this case means cultural rather than natural selection. While such anecdotal evidence as I described above might not be taken too seriously, it seems that I am not alone in wondering about the direction and theoretical foundations of such work. In an aptly titled paper, "Drunk in an orgy of technology", Professor Chris Wise, who, amongst other distinguished roles, advises the Emergent Technologies and Design programme at the Architectural Association, pinpoints the same problem:

“....even with today's 'fab' computers we are utopia-bytes short of enough computing power to study what we really want to study, so the computer goes along a very narrow path. It only stops when its told to. Mimicking Darwin, computerized mutations jump the process into another groove in the hope that somehow the fittest will survive. But the definition of 'fitness' is usually arbitrary, so the tools stunt their own creativity" (56).

Wise's cautionary note, however, is rare in a field where researchers and admiring critics alike are generally so enamoured with the glossy products of these machinations, that they rarely question the underlying assumptions of evolutionary validity. It may be useful at this juncture, therefore, to take another look at the Darwinian model, which, as Wise implies, is the main source of inspiration for much, if not all of this kind of work.

\section{Memetic Perspective}

I shall approach my subject from a memetic perspective, a relatively new body of knowledge and research kick-started by Richard Dawkins with his seminal book, The Selfish Gene. In that book, Dawkins proclaimed that Darwin's theory of evolution is too rich to be confined to natural selection alone, and should be broadened to include human culture. This in itself is not new. Neo-Darwinian analogies of one kind or another have been popular in most fields, including architecture and planning (Alexander; Collins; Abel, "Evolutionary"), ever since Charles Darwin completed On the Origin of Species. However, Dawkins went well beyond metaphorical allusions to identify distinct or particulate units of culture, which he called memes, after the Greek root for mimic, which replicate themselves in similar ways to genes:

"If I had to bet, I would put all my money on one fundamental principle. This is the law that all life evolves by the differential survival of replicating entities" (191-192).

Following Dawkins' lead, the philosopher Paul Dennett has drawn attention to the abstract features of Darwin's theory, which can be generalised beyond its original range of application. According to Dennett, natural selection boils down to a simple but highly effective process familiar to any computer programmer:

"The theoretical power of Darwin's abstract scheme was due to several features that Darwin firmly identified, and appreciated better than many of his supporters, but lacked the terminology to describe explicitly. Today we would capture these features under a single term. Darwin had discovered the power of algorithm" (50).

As Dennett points out, algorithms were already familiar in Darwin's day as mathematical and logical procedures, but it was Alan Turing's work in the 1930s and the great strides in computer science made since then, that confirmed the universal power of the logical structure. Algorithms, Dennett explains, like fool-proof recipes, are nothing more nor less than step by step procedures for achieving a specific, guaranteed result: do this, then this, followed by that, and you will get this result. Natural selection works according to the same simple rules of logic. Susan Blackmore, another leading light in memetics, neatly sums up the whole process:

"As Darwin realized, a simple reiterative process can create the most intricate and functional designs apparently out of nowhere (author's emphasis). It works like this - 
start with something; make lots of copies of it with slight variations; select just one of these; and then repeat the process. That's all.

The power lies with the effect of selection....in a world with insufficient food, space, light, and air to go round, inevitably some creatures will do better than others, and whatever it was that helped them in the competition for survival will be passed on to their offspring, and so the process continues. As it does, characteristics such as eyes, wings, hair, and teeth all appear and evolve. These are the adaptations that helped the animals to survive, and will be passed on if they breed" ("Consciousness" 124).

\section{Theoretical Problems}

So far; so good. There is nothing in any of the above to cast doubt on the wisdom of using genetic algorithms in design, or indeed in any other field. On the contrary, quite literally, it would seem to be the logical thing to do for anyone interested in how things evolve and change, whether they are organisms or cultures.

However, as the burgeoning literature in memetics shows (Aunger), not to mention shots from the sidelines from social anthropologists and others critical of the new discipline (Bloch), Universal Darwinism, as it is called, and comparisons between genes and memes in particular, are fraught with theoretical and empirical problems. To begin with, definitions of what memes, as cultural replicators, actually consist of, are notoriously vague, and include anything from catchy tunes and fashions to major culture-forms like religion - a favourite topic, or rather, target of Dawkins. Moreover, unlike the chemically precise replication of genes from generation to generation, it is difficult if not impossible to trace any equally precise process of reproduction, or imitation, as Dawkins describes it, that applies to all human cultures. According to some sceptical writers, like Dan Sperber, this alone threatens the legitimacy of the whole memetics enterprise.

In addition to the problem of selection referred to at the beginning of this paper, we therefore have two further issues to contend with. Following Blackmore ("Meme"), I shall call these the problem of definition, and the problem of transmission. However, there are still other reasons to question any close likeness between genes and memes. A clear distinction is made in genetic evolution between the genotype, which is the total make-up of genes in each organism, and the sum-total of the various hereditary characteristics of the organism, known as the phenotype, which is the product of the information carried by the genes. Natural selection favours those genes whose phenotypic effects give the organism some kind of advantage over organisms lacking those same attributes, i.e., whose genes produce less robust effects. Although it is the genes, as efficient replicators, which are actually transmitted through the generations, it is the effects or characteristics they produce in the organism that determine their survival.

Natural selection therefore works only indirectly on genes, through their phenotypic effects. If the analogy between genes and memes is to hold, then a similar distinction must also hold between memes and their own effects. This requires not only a particulate meme as a distinct unit of culture, but also a selection process that acts indirectly on the meme through its effects. I shall call this the problem of embodiment.

Last but not least, there is the problem of autonomy. According to Dawkins, bodily organisms are merely convenient vehicles, or 'survival machines', as he calls them, assembled by genes for their own benefit and procreation through their phenotypic effects. Accordingly, the primary targets of natural selection are neither the species nor the group, as evolutionary biologists generally assume, but the genes themselves. Furthermore, genes will always behave selfishly, so to speak, and choose that form or configuration in nature that most favours their own procreation.

Throughout these arguments, Dawkins stresses that, while memes, like genes, might appear at least from the explanatory language used - to exhibit some kind of purposeful behaviour, this is no more than a useful metaphor, and should not be taken literally to imply any kind of conscious direction. Selection simply acts upon both genes and memes in such a manner that those replicators having the most favourable effects on their chances for survival will inevitably proliferate, and thus behave 'as if' they were active agents in their own fate. Yet it is equally clear from Dawkins' treatment of other aspects of the meme-gene analogy that he regards the comparison with genetic evolution as more than a metaphor, and that memes, like genes, are literally subject to many, if not all of the same harsh laws of Darwinian selection. 


\section{Key Issues}

At the core of these debates are more fundamental questions of the validity of Universal Darwinism itself, and how far Darwinian models of evolution can be fruitfully applied to such diverse phenomena as organisms and human culture-forms, including buildings and other artefacts. I believe that they are applicable, so long as we respect the differences as well as the similarities between genes and memes. Taking each of the five main problems identified above, the key issues can be set out as follows.

\subsection{The Problem of Definition}

Memeticists are generally agreed that the evolution of humankind differs radically from that of other species, primarily by the nature of their diverse culture-forms and the dominant use of symbolic systems in the organization of knowledge and customary behaviours. Beyond this, however, they are divided over how memes, as cultural entities, should be defined or how they function. Those with a background in psychology, like Blackmore, believe that memes are mental entities and will eventually be located within the workings of the brain by advances in the neurosciences. Others from different disciplines, like Dennett, believe that memes can only be identified through their external cultural manifestations, whether they are forms of behaviour, symbolic systems or artefacts, and have no separate existence. Once these die, so does the meme. In either case, it seems unlikely that memes will ever be defined with the same precision as genes.

Like Kate Distin, I take the position that memes are special kinds of ideas, involving generally applicable concepts, like types, such as tools, clothes; games; dances; disciplines, and, of course, building types and styles (I interpret styles as a different kind of type from the building variety). However, types, as symbolic systems, only have meaning within broader systems of related ideas. The concept of memes as types therefore challenges the notion of memes as particulate or isolable units of culture, comparable with genes as particulate units. In this respect, therefore, memes differ significantly from genes.

\subsection{The Problem of Transmission}

Amongst the conditions that memes have to meet in order to fulfil their function and transmit their information effectively from person to person and generation to generation, Dawkins stipulated that memes, like genes, should be capable of being copied with a high degree of fidelity. Hence the popularity amongst some memeticists for examples based on the use of modern techniques of reproduction, like printing, photography, photo-copying and computer programs. However, a general theory of cultural evolution cannot be restricted to memes that can only be transmitted or disseminated with modern technologies.

As with the problem of definition, the requirement for absolute fidelity of replication needs to be relaxed in order to accommodate the complexities and diverse methods of cultural transmission. Here I am in agreement with Sperber, who argues that memes are not so much simply copied, as reconstructed by inference, a complex psychological process involving the attribution of intentionality, as well as learning skills. However, while this might seem to weaken Dawkins' original theory of memetic transmission, unlike Sperber, I do not believe that it threatens the basic idea of memes as replicators, albeit the process of replication may be far more complex than Dawkins conceived it to be. The creative process of inference and reconstruction also allows ample room for variations and mutations - an essential ingredient in the Darwinian model - whilst transmitting essential features of the type accurately enough for it to be easily identified, despite the variations.

\subsection{The Problem of Embodiment}

Reconstruction by inference implies the existence of some kind of publicly accessible evidence indicating what a meme consists of, so that it can be reproduced. Likewise, inferring the intentions of the person or persons who created the form that is being replicated, or reconstructed, also requires some kind of external evidence of those intentions, normally obtained by observation, i.e., listening to the music or seeing the artefact itself. I maintain, with George Kubler, that artefacts, like other culture-forms, owe their identity primarily as one of a series of similar artefacts, or what Kubler calls 'linked problem solutions'. Accordingly, being able to infer the defining attributes of a meme requires the evidence of several exemplars, rather than any single case, so that the essential characteristics of the type can be sifted out from its variations. This of course is precisely what we do as teachers or critics when we explain 
a particular building type or style to students and designers, who may wish to reproduce that specific form, or at least understand it.

A distinction can therefore be made between memes and their vehicles, comparable with that made between genes and their vehicles, though, as with other comparisons, it should not be taken too literally. In this case, since a type cannot be identified with a single exemplar, it clearly exists in some sense beyond that specific vehicle. However, a gene has a tangible physical existence distinct from its vehicles, whereas a meme only exists as a separate entity when it is inferred and reconstructed from several of its own vehicles. Compared to genes, memes are rather ghost-like entities, only appearing briefly in the act of reconstruction.

\subsection{The Problem of Selection}

In the closing passage of his chapter on memes in The Selfish Gene, Dawkins breaks with the generally passive picture of Darwinian selection:

"We are built as gene machines and cultured as meme machines, but we have the power to turn against our creators. We, alone on earth, can rebel against the tyranny of the selfish replicators" (201).

However, in rightly rejecting a too-passive view of human evolution, Dawkins may have veered too far in the opposite direction. As with similarly optimistic statements, Dawkins' declaration of faith in the power of human choice is little more than that - a declaration of faith - rather than a concept or theory supported by evidence (it's a bit ironic, to say the least, that such a statement should come from an avowed enemy of faith-based beliefs). Unfortunately, the historical evidence on the fate of many past civilizations presented by Jared Diamond, suggests a far less rosy future than that held out by Dawkins.

A more balanced and realistic view of how Darwinian selection works, in both the natural and human worlds is offered by Kevin Laland and John Odling-Smee in their theory of 'nicheconstruction'. Taking up Dawkins' suggestion that an organism's phenotypic effects extend beyond the body of an organism to include all its effects on the world ("Phenotype"), Laland and Odling-Smee point out that, by building dams or shelters or otherwise modifying their environments, beavers and countless other creatures significantly affect the selection pressures acting on their development. Evolution is therefore a two-way process, rather than the one-way process portrayed in the conventional passive picture.

In the same way, by modifying their environments, whether through agriculture, communication systems, or building cities, humans also affect their own selection pressures. However, for better or worse, the same modified environments create new selection pressures of their own, which may actually restrict freedom of action, rather than create more choices.

\subsection{The Problem of Autonomy}

Just as Dawkins argued that we can only understand the way biological evolution works by reversing the usual focus on the organism and adopting the 'gene's eye view', so he also argues that we can only understand the way cultures evolve by adopting the 'meme's eye view'. What this means in practice is accepting the difficult notion that memes and meme-complexes may have autonomous or semi-autonomous lives of their own. As Dawkins puts it: "A cultural trait may have evolved in the way it has simply because it is advantageous to itself" ("Gene" 214).

Similar notions of autonomous behaviour drive the growing interest in theories of emergence and self-organizing systems (Fraser; Hensel, Menges and Weinstock), as well as the interest in genetic algorithms, to which they are sometimes related. I maintain that the apparently autonomous emergence and development of cultural traits and types is an outcome of the same recurring cycle of positive feedback described above: of modified environments affecting selection pressures, leading to new traits and types, which in turn lead to further modifications of the cultural environment, affecting selection pressures again, and so on, ad infinitum.

Innovations may also be better understood from the same perspective. Rather than being the sole province of creative individuals, as it is normally portrayed, I hold that the process of innovation is a spontaneous outcome of new selection pressures, in which new ideas and technologies are generated in response to a changing social and cultural environment, which in turn leads to new selection pressures, etc. Amongst other factors, I believe that the simultaneous discovery of the same idea or invention by different persons working separately, of which there are some famous instances in the development of evolutionary biology itself, as 
well as in many other fields, offers ample evidence for my theory. In short, if an idea's time has come, if you don't come out with it, somebody else will!

\section{Embedded algorithms}

Given all these problematic issues, it must be asked, are evolutionary models of design based on genetic algorithms simply abstract versions of real-world processes, as their protagonists claim them to be, or are the differences between cultural and genetic evolution so great as to suggest that such models are fundamentally misconceived, or, at least misleading?

I hasten to add that, personally speaking, I have no problem with the evident preoccupation in these exercises with baroque form as such. There have always been designers who put formal and aesthetic issues before everything else, consciously or unconsciously. Lynn's interest in the ornamental aspects of design is also well documented ("Ornament"). However, I suspect that much of the attraction of genetic algorithms - for students as well as for their teachers - lies in the illusion of authority accruing to the design from the algorithm, which the genetic model, as I have explained, may not merit.

An alternative strategy would be to embed design algorithms in real-life projects, as Chris Williams did with the design for the roof over the Great Court in the British Museum, so exposing the selection process to a wider range of environmental issues, both cultural and material. Wise also suggests something of the kind when he calls for more project-related experiments:

"So far, the emerging technologist has usually had to limit the output of the process to an object rather than a project. A project has a definite purpose. A project has a site. A project interacts with people. It interacts with climate. It interacts with time. And unlike a computer process it is made of imperfect things and materials that change according to this interaction. In short, the project lives" (57).

Parametric modelling, as used by cutting edge practices like those of Norman Foster and Frank Gehry, already does much of the job (Abel, "Technology"; Abel, "Ecologies"; Burry; Glymph; Whitehead). While it automates many complex and time-consuming design processes, unlike genetic algorithms, it has the built-in virtue of permeability. That is to say, it facilitates and encourages external human and environmental inputs of virtually any kind at any stage of the development process, adjusting design parameters along the way.

\section{Conclusions}

Beyond such ad hoc developments, however, I am doubtful there will be any significant progress in understanding how architecture, or indeed any other culture-form evolves, so long as researchers remain fixated solely on the genetic model. While the clarity and precision characteristic of computer algorithms might accurately simulate the precision of genetic replication, they hardly reflect the far less exact and ambiguous processes that characterize the evolution of cultures. In sum, the proper subjects of study for design research are memetic algorithms rather than the genetic variety (Abel "Cultural Evolution"). Though they might lack the mystique of the latter, with all their pretensions to precision engineering, as models of cultural evolution they are more likely to be relevant to our real needs.

\section{References}

Abel, Chris. "Evolutionary Planning." Architectural Design, December 1968. 563-564.

Abel, Chris. "Electronic Ecologies." Norman Foster: Works 4. Ed. David Jenkins. London: Prestel, 2004. 12-29.

Abel, Chris. Architecture, Technology and Process. Oxford: Architectural Press, 2004.

Abel, Chris. Architecture and Cultural Evolution. Forthcoming.

Alexander, Christopher. Notes on the Synthesis of Form. Cambridge: Harvard University Press, 1964.

Aunger, Robert. Darwinizing Culure: The Status of Memetics as a Science. Oxford: Oxford UP, 2000.

Blackmore, Susan. The Meme Machine. Oxford: Oxford UP, 1999.

Blackmore, Susan. Consciousness. Oxford: Oxford UP, 2005. 
Bloch, Maurice. "A Well-disposed Social Anthropologist's Problems with Memes." Darwinizing Culture: The Status of Memetics as a Science. Op cit. 189-203.

Burry, Mark. "Between Intuition and Process: Parametric Design and Rapid Prototyping". Architecture in the Digital Age: Design and Manufacturing. Ed. Branko Kolarevic. London: Taylor \& Francis, 2003. 54-57.

Collins, Peter. Changing Ideals in Modern Architecture. London: Faber and Faber, 1965.

Darwin, Charles. On the Origin of Species. New York: Atheneum, 1859; 1972.

Dawkins, Richard. The Selfish Gene. Oxford: Oxford UP, 1976;1989.

Dawkins, Richard. The Extended Phenotype. Oxford: Oxford UP, 1982;1999.

DeLanda, Manuel. "Deleuze and the Use of the Genetic Algorithm in Architecture." Designing for a Digital World. Ed., Neil Leach. Chichester: Wiley-Academy, 2002. 117-120.

Dennett, Daniel C. Darwin's Dangerous Idea: Evolution and the Meanings of Life. London: Penguin Books, 1995; 1996.

Diamond, Jared. Collapse: How Societies Choose to Fail or Survive. London: Allen Lane, 2005.

Distin, Kate. The Selfish Meme. Cambridge: Cambridge UP, 2005.

Fraser, John. An Evolutionary Architecture. London: Architectural Association, 1995.

Glymph, Jim. "Evolution of the Digital Design Process." Architecture in the Digital Age: Design and Manufacturing. Op. cit. 102-120.

Hensel, Michael, Menges, Achim and Weinstock, Michael, eds. Emergence: Morphogenetic Design Strategies. Chichester: Wiley-Academy, 2004.

Johansen, John M. Nano Architecture. New York: Princeton Architectural Press, 2002.

Kubler, George. The Shape of Time. New York: Yale UP, 1962.

Laland, Kevin, and Odling-Smee, John. "The Evolution of the Meme." Darwinizing Culture: The Status of Memetics as a Science. Op. cit. 121-141.

Lynn, Greg. "The Structure of Ornament." Digital Tectonics. Eds., Neil Leach, David Turnbull and Chris Williams. Chichester: Wiley-Academy, 2004. 62-68.

Lynn, Greg. Untitled lecture at the Town Hall, Sydney, organized by the Year of the Built Environment 2004, NSW Secretariat, September 28, 2004.

Sperber, Dan. "An Objection to the Memetic Approach to Culture." Darwinizing Culture: The Status of Memetics as a Science. Op. cit. 163-173.

Stace, Sara, ed. Houses of the Future. Sydney: Year of the Built Environment 2004, NSW Secretariat, 2004.

Whitehead, Hugh. "Laws of Form." Architecture in the Digital Age: Design and Manufacturing. Op. cit. 82-100.

Williams, Chris. "Design by Algorithm." Digital Tectonics. Op cit. 78-85.

Wise, Chris. "Drunk in an Orgy of Technology." Emergence: Morphogenetic Design Strategies. Op cit. 54-57. 